\title{
WS15-C03
}

\section{Simultaneous Acquisition of DAS and Conventional Down-hole Geophone Array at Aqusitore, Canda}

\author{
J.D. Cocker (Chevron), E.F. Herkenhoff (Chevron), M.E. Craven (Chevron), \\ T. Nemeth (Chevron), T.M. Daley (LBNL), D. White (Geological Survey of \\ Canada) \& A. Strudley* (Chevron)
}

\section{SUMMARY}

A 3D VSP was acquired in Nov 2013 to quantify the sensitivity, directivity and coupling characteristics of Distributed Acoustic Sensing (DAS) data relative to conventional borehole geophones. This trial leveraged a collaborative research agreement between Chevron, Lawrence Berkeley National Labs and the Aquistore CO2 sequestration project in Saskatchewan run by the Petroleum Technology Research Centre (PTRC). 


\section{Amsterdam ' 14}

\section{Introduction}

A 3D VSP was acquired in Nov 2013 to quantify the sensitivity, directivity and coupling characteristics of Distributed Acoustic Sensing (DAS) data relative to conventional borehole geophones. This trial leveraged the prior experience of Lawrence Berkeley National Labs with DAS (Daley et al, 2013) and a collaborative research agreement between LBNL, Chevron, and the Aquistore CO2 sequestration project in Saskatchewan run by the Petroleum Technology Research Centre (PTRC).

\section{Method}

Data from a 3D grid of explosives and a 2D line of Vibroseis were simultaneously acquired with a 60 level Sercel MaxiWave tool and DAS in the same observation borehole (Figure 1). DAS was recorded on single and multimode fiber optic cables that were contained in the same bundle and cemented behind casing. Figure 2 shows a DAS shot record.

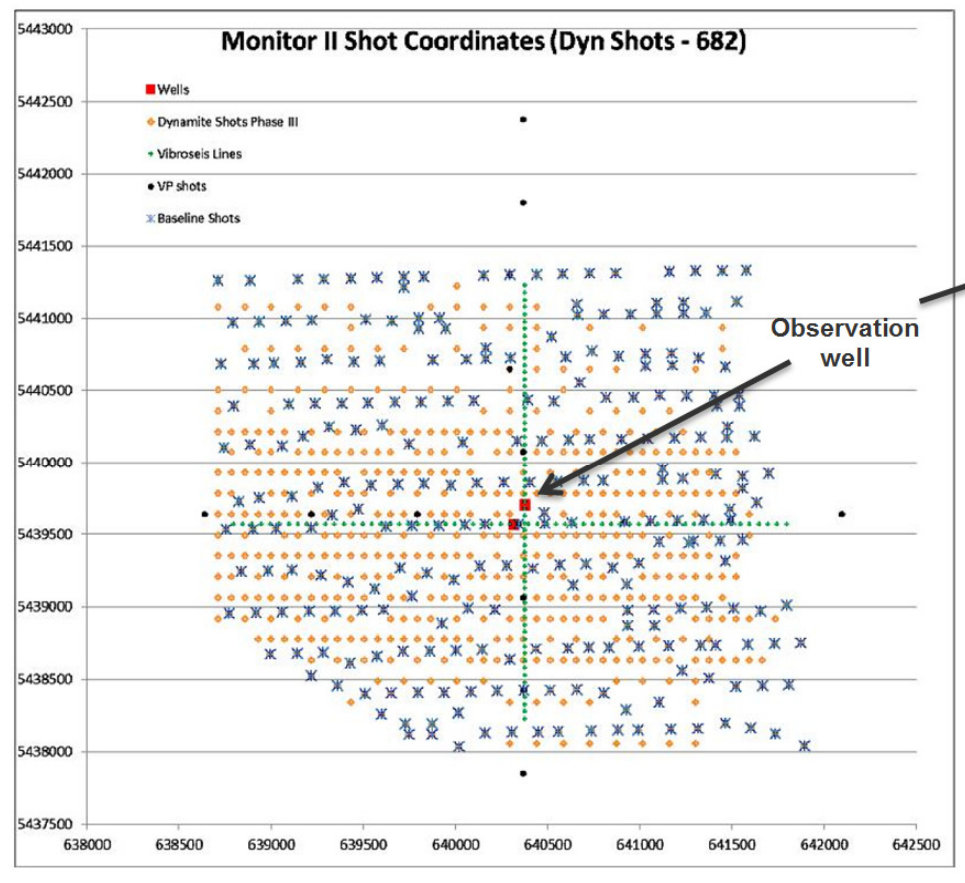

a) Planned shot-point grid

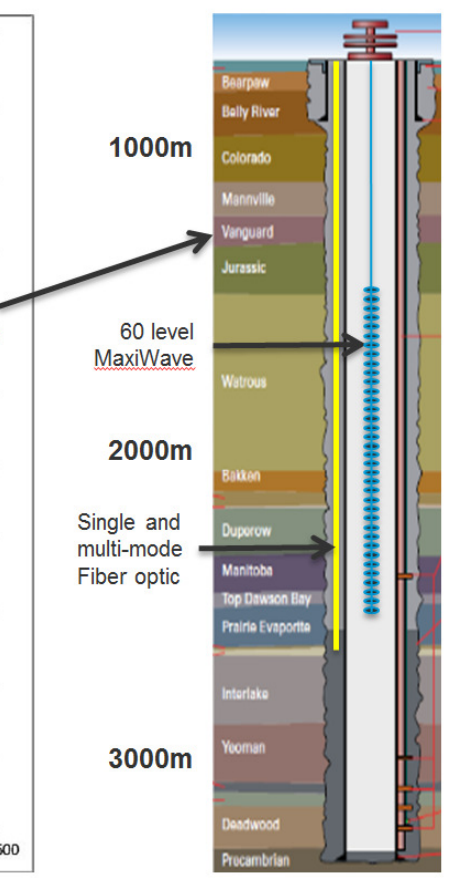

b) Observation well receivers

Figure 1 a) Source grid, and b) Fibre Optic and down-hole geophone layout. 


\section{Amsterdam ' 14}

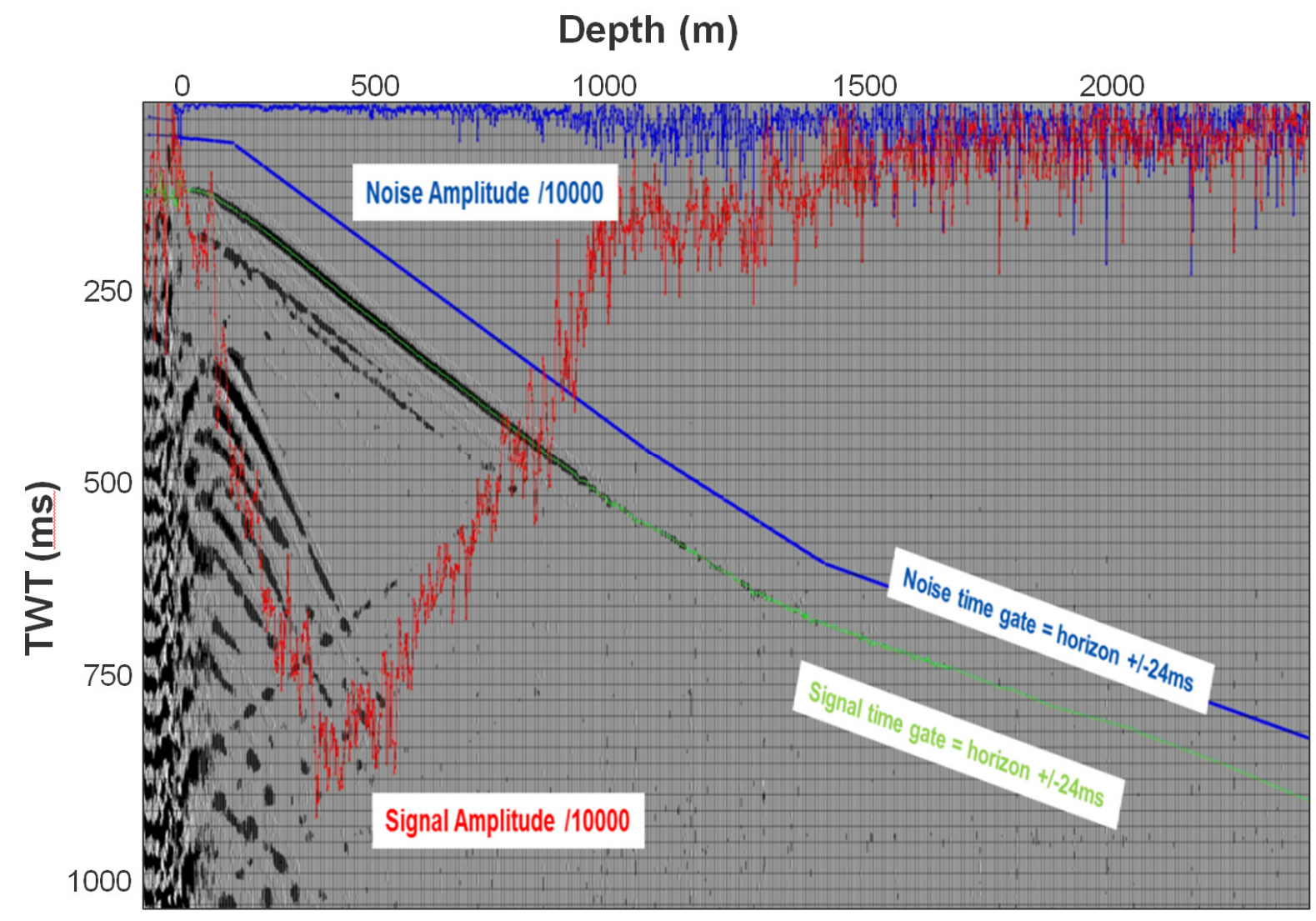

Figure 2 DAS data showing relatively strong first breaks down to $1000 \mathrm{~m}$.

Note: RMS amplitudes increase downwards.

\section{Conclusions}

The collaborative research approach was a win-win for all involved. It provided PTRC with additional funds to acquire a comprehensive baseline 3D VSP, and LBNL and Chevron an opportunity to simultaneously acquire DAS and conventional geophone data in a very short time frame. Field data has only just been delivered, but initial observations confirm that the S/N of DAS data is significantly lower than the geophone data, particularly at higher frequencies. The direct arrivals on DAS data have good $\mathrm{S} / \mathrm{N}$ in the first $1000 \mathrm{~m}$ but the amplitude diminishes sharply for non-axial particle motion, particularly in the shallow part of the well where the signal arrives broadside.

\section{References}

Daley, T., Freifeld, B., Ajo-Franklin, J., Dou, S., Pevzner, R., Shulakova, V., Kashikar, S., Miller, D., Goetz, J., Henninges, J. and Lueth, S. [2013] Field testing of fiber-optic distributed acoustic sensing (DAS) for subsurface seismic monitoring. The Leading Edge, 32 (6), 699-706. 